\title{
Tramadol Ultra Rapid Metabolizers at Risk for Respiratory Depression
}

\section{TO THE EDITOR:}

Re: "A Costly Lesson: Fatal Respiratory Depression Induced by Clindamycin during Postoperative Patient Controlled Analgesia" Pain Physician 2015; 18:E429-E431

In regards to a recent article by Gao Wu and colleagues (1), the authors fail to recognize the potential of tramadol infusion contributing to the patient's respiratory depression and cardiac arrest. Tramadol is a relatively safe centrally acting analgesic devoid of any serious adverse events associated with traditional opioids via respiratory depression and dependence. However, tramadol is a prodrug for the active metabolite $\mathrm{O}$ desmethyltramadol (O-DSMT), which together with the parent compound, acts by binding mu opioid receptors and inhibiting the reuptake of serotonin and norepinephrine. In a subset population, notably patients who are P450 CYP2D6 ultra rapid-metabolizers, tramadol has been associated with near fatal respiratory depres- sion and cardiotoxicity (2).

This patient received a basal rate of $10 \mathrm{mg} / \mathrm{hour}$ of Tramadol with $20 \mathrm{mg}$ bolus dose at a lockout interval of 30 minutes. Total 24 hours PCA dose of tramadol was $500 \mathrm{mg}$. The elimination half-life of O-DSMT is near 7 hours. If patient was an ultra-rapid metabolizer, increasing the level of O-DSMT and possible blood epinephrine levels could have contributed to her demise.

\author{
Gurpreet Dhaliwal M.D. \\ Department of Anesthesiology \\ Harbor UCLA Medical Center \\ Torrance, California \\ Email: gdhaliwal02@gmail.com \\ Dora Hsu M.D. \\ Departement of Anesthesiology \\ Harbor UCLA Medical Center \\ Email: dthsu2@gmail.com
}

\section{References:}

1. Wu G, Wu G, Wu H. A costly lesson: Fatal respiratory depression induced by clindamycin during postoperative patient controlled analgesia. Pain Physician
2015: 18:E429-E431.

2. Elkalioubie $A 1$, Allorge $D$, Robriquet $L$, Wiart JF, Garat A, Broly F, Fourrier F. Near-fatal tramadol cardiotoxicity in a
CYP2D6 ultrarapid metabolizer. Eur ] Clin Pharmacol 2011; 67:855-68. Epub 2011 Jun 21. 